\title{
Identification, isolation, and expression analysis of heat shock transcription factors in the diploid woodland strawberry Fragaria vesca
}

\author{
Yang $\mathrm{Hu}^{1,2}$, Yong-Tao Han ${ }^{1}$, Wei Wei ${ }^{1,2}$, Ya-Juan $\mathrm{Li}^{1}$, Kai Zhang ${ }^{1,2}$, Yu-Rong Gao ${ }^{1}$, \\ Feng-Li Zhao ${ }^{1}$ and Jia-Yue Feng ${ }^{1,2 *}$
}

${ }^{1}$ State Key Laboratory of Crop Stress Biology for Arid Areas, College of Horticulture, Northwest A\&F University, Yangling, Shaanxi, China, ${ }^{2}$ Key Laboratory of Protected Horticulture Engineering in Northwest China, Ministry of Agriculture, Yangling, Shaanxi, China

OPEN ACCESS

Edited by:

Vasileios Fotopoulos,

Cyprus University of Technology,

Cyprus

Reviewed by:

George A. Manganaris,

Cyprus University of Technology,

Cyprus

Elisabetta Mazzucotelli,

Consiglio per la Ricerca e

Sperimentazione in Agricoltura, Italy

*Correspondence:

Jia-Yue Feng,

College of Horticulture, Northwest A\&F University, No.3 Taicheng Road,

Yangling 712100, Shaanxi, China

fengjy19151@nwsuaf.edu.cn

Specialty section:

This article was submitted to Crop Science and Horticulture,

a section of the journal

Frontiers in Plant Science

Received: 15 June 2015

Accepted: 29 August 2015 Published: 15 September 2015

Citation:

Hu Y, Han Y-T, Wei W, Li Y-J, Zhang K,

Gao $Y$-R, Zhao F-L and Feng J-Y (2015) Identification, isolation, and expression analysis of heat shock transcription factors in the diploid woodland strawberry Fragaria vesca.

Front. Plant Sci. 6:736.

doi: 10.3389/fpls.2015.00736
Heat shock transcription factors (Hsfs) are known to play dominant roles in plant responses to heat, as well as other abiotic or biotic stress stimuli. While the strawberry is an economically important fruit plant, little is known about the Hsf family in the strawberry. To explore the functions of strawberry Hsfs in abiotic and biotic stress responses, this study identified 17 Hsf genes (FvHsfs) in a wild diploid woodland strawberry (Fragaria vesca, $2 n=2 x=14$ ) and isolated 14 of these genes. Phylogenetic analysis divided the strawberry FvHsfs genes into three main groups. The evolutionary and structural analyses revealed that the FvHsf family is conserved. The promoter sequences of the FvHsf genes contain upstream regulatory elements corresponding to different stress stimuli. In addition, 14 FvHsf-GFP fusion proteins showed differential subcellular localization in Arabidopsis mesophyll protoplasts. Furthermore, we examined the expression of the $17 \mathrm{FvHsf}$ genes in wild diploid woodland strawberries under various conditions, including abiotic stresses (heat, cold, drought, and salt), biotic stress (powdery mildew infection), and hormone treatments (abscisic acid, ethephon, methyl jasmonate, and salicylic acid). Fifteen of the seventeen FvHsf genes exhibited distinct changes on the transcriptional level during heat treatment. Of these 15 FvHsfs, 8 FvHsfs also exhibited distinct responses to other stimuli on the transcriptional level, indicating versatile roles in the response to abiotic and biotic stresses. Taken together, the present work may provide the basis for further studies to dissect FvHsf function in response to stress stimuli.

Keywords: strawberry (Fragaria vesca), heat shock transcription factor, expression analysis, subcellular localization, heat stress, abiotic stress, phytohormones

\section{Introduction}

Global warming has brought about many severe environmental problems with adverse impacts on almost all aspects of plant development, growth, reproduction, or yield (Hedhly et al., 2009; Mittler et al., 2012). Although plants are sessile organisms that cannot escape from stress conditions, a cascade of activities regulated by transcription factors are triggered in response to such conditions (Schwechheimer and Bevan, 1998). Particularly, plant heat shock transcription factors (Hsfs) are 
known to play a central role in protecting plants from heat or other stress conditions (Scharf et al., 2012).

Hsfs are structurally conserved throughout the eukaryotic kingdom. Earlier studies focusing on the structural and biochemical characteristics of Hsfs (Harrison et al., 1994; Littlefield and Nelson, 1999) revealed that a typical Hsf consists of five conserved motifs, including a DNA-binding domain (DBD), an oligomerization domain (OD), a nuclear localization signal (NLS), a nuclear export signal (NES), and an activator peptide motif (AHA) (Never et al., 1996; Scharf et al., 2012).

A number of studies have demonstrated that Hsfs play vital roles in plant responses to abiotic stresses such as heat, cold, salt, drought, and oxidative conditions, among others (Schramm et al., 2008; Yoshida et al., 2010; Hwang et al., 2014). For example, a versatile regulatory regime involving HsfA1, HsfA2, HsfBla, Hsp90, and Hsp70 in the control of heat stress response was proposed (Hahn et al., 2011). HsfA2 serves as the most strongly induced $\mathrm{Hsf}$, accumulating to high levels after exposure of tomato (Chan-Schaminet et al., 2009), Arabidopsis (Schramm et al., 2006), or rice (Mittal et al., 2009) to long-term heat stress. Substantial evidence has also demonstrated that HsfA2 is associated with the expression of multiple Hsps or general stress-related non-chaperone encoding genes (Schramm et al., 2006; Chan-Schaminet et al., 2009; Nishizawa-Yokoi et al., 2009). HsfA3 is located downstream of the DREB2A stress-regulatory system in the transcriptional cascade (Schramm et al., 2008) and could be involved in physiological responses to drought and salt stress (Li et al., 2013). HsfA4 was reported to be involved in oxidative stress (Davletova et al., 2005) and cadmium tolerance in rice and wheat (Shim et al., 2009). HsfA6a and HsfA6b expression is highly increased under high salinity or dehydration conditions (Yoshida et al., 2010; Hwang et al., 2014). In addition, HsfB1a and $\mathrm{HsfB} 2 \mathrm{a} / \mathrm{b}$ were reported to be associated with pathogen resistance in Arabidopsis (Kumar et al., 2009; Ikeda et al., 2011; Pick et al., 2012). In addition to stress resistance, Hsfs have also been linked to important roles in plant growth and development (Kotak et al., 2007; Almoguera et al., 2009). Recently, genome-wide expression profiles analyses in rice (Mittal et al., 2009), wheat (Xue et al., 2014), soybean (Chung et al., 2013), and apple (Giorno et al., 2012) also indicated that several $H s f$ genes were transcribed at high levels during heat, cold, salt, and drought stresses. However, little is known about $H s f$ genes in the strawberry.

The strawberry is one of the most important fruit crops in the world. However, more extreme temperatures and droughts, serious fungal infections and secondary salinization have strongly limited the growth, development, reproduction, and yield of strawberry plants in recent years (Maughan et al., 2015; Nezhadahmadi et al., 2015). The woodland strawberry F. vesca has a smaller genome $(\sim 240 \mathrm{Mb})$ that is highly congenic with its octoploid cultivated species (Fragaria $\times$ ananassa Duch.) (Shulaev et al., 2011). These features underlie its potential utility as a versatile experimental system for studying the counterparts of many important genes in Rosaceae fruit crops (Shulaev et al., 2011; Liu et al., 2014).

To explore the functions of Hsfs in abiotic and biotic stress responses in the strawberry, the current study identified and isolated $F v H s f$ genes in a diploid woodland strawberry accession
Heilongjiang-3 (Liu et al., 2014), in addition to analyzing the evolutionary relationships, gene structure, protein domains, and expression profiles of these genes with respect to heat, drought, salt, cold, and powdery mildew infection stresses and abscisic acid, ethephon, methyl jasmonate, and salicylic acid treatments. Notably, the subcellular localization of most (14/17) of the FvHsf proteins was demonstrated; these data have not been fully elucidated in any other plant species. Taken together, the present work may provide the basis for further studies to dissect $F v H s f$ function in response to abiotic or biotic stresses.

\section{Materials and Methods}

\section{Identification and Classification of Hsf Genes in Strawberry}

A publicly available database (http://planttfdb.cbi.pku.edu.cn/) predicted that $15 \mathrm{Hsf}$ genes exist in the diploid strawberry genome (accession Hawaii-4) and predicted the corresponding nucleotide and amino acid sequences. All of the nucleotide and amino acid sequences of the predicted $F v H s f$ genes were used as queries to perform BLAST searches in the public NCBI database. The strawberry genes with the highest identity (>90\%) and lowest $E$-value (0) were selected as candidates. If two or more protein sequences at the same gene locus overlapped, only the longest sequence was used. All of the putative candidates were manually verified with the InterProScan program (http://www.ebi.ac.uk/Tools/pfa/iprscan/) to confirm their completeness and the presence of a DNA-binding domain (PF00447) (http://pfam.sanger.ac.uk/).

Phylogenetic analysis was used to classify the FvHsf genes into three classes and further subclasses (Scharf et al., 2012). The fulllength amino acid sequences of Hsf proteins from strawberry $(F v H s f)$, A. thaliana (AtHsf), rice (Oryza sativa L., OsHsf) (Guo et al., 2008), apple (Malus domestica Borkh, MdHsf) (Giorno et al., 2012), and grape (Vitis vinifera, VvHsf) were used to generate a phylogenetic tree through ClustalW alignment and the unrooted Neighbor-joining method using MEGA 5.0 (Tamura et al., 2011). Neighbor-joining analysis with pairwise deletion was performed using the Jones-Taylor-Thornton (JTT) model. Bootstrap analysis was performed with 1000 replicates to assess the level of statistical support for each tree node (Xue et al., 2014).

\section{Gene Structure, Protein Domains, and Synteny Analysis of Strawberry Hsf Genes}

The exon-intron structures of $F v H s f$ genes were visualized using the online program GSDS 2.0 (http://gsds.cbi.pku.edu.cn/), which aligns the respective coding sequences with corresponding full-length sequences. The protein domains of the FvHsf genes were identified using MEME online tools (http://meme.nbcr.net/meme/) with the parameters set as follows: the minimum length of the conserved motif was 6 , the maximum length of the conserved motif was 100 , and the largest number of discovered and conserved motifs was 25 . The other parameters retained their default settings. The results were presented by DOG 1.0 (Ren et al., 2009). The syntenic blocks used to construct a synteny analysis map between the strawberry and Arabidopsis Hsf genes were obtained from the Plant 
Transcription Factor Database (http://planttfdb.cbi.pku.edu.cn/) and Plant Genome Duplication Database (Lee et al., 2013), and the diagrams were generated by the Circos program, version 0.63 (http://circos.ca/).

\section{Isolation and Subcellular Localization of Strawberry Hsf Genes}

To provide more insight into the function of $F v H s f s$, we designed gene-specific primers to isolate the putative $H s f$ genes from a diploid woodland strawberry accession Heilongjiang-3. The predicted full-length coding sequences of FvHsf genes were amplified from Heilongjiang-3 cDNA using high-fidelity Taq HSmediated PCR. Then, we used the isolated $F v H s f s$ to examine the subcellular localization of these proteins. The amplified PCR products were digested with $\mathrm{XbaI} / \mathrm{XhoI}$ and $\mathrm{Kp} n \mathrm{I}$ and fused in-frame with GFP in the $\mathrm{XbaI} / \mathrm{XhoI}$ and $\mathrm{Kp} \mathrm{I}$ site of the pBI221 vector containing the CaMV $35 S$ promoter (Clontech, Beijing, China), resulting in the pFvHsf-GFP plasmids. The primers used to clone genes and construct vectors are available in Supplementary Table S1.

For the transient expression of FvHsfs-GFP in Arabidopsis mesophyll protoplasts, the corresponding pFvHsfs-GFP plasmid was transformed into Arabidopsis mesophyll protoplasts using the PEG-calcium transfection method described in Yoo et al. (2007). After transformation, the Arabidopsis mesophyll protoplasts were kept in darkness at room temperature for $16-18 \mathrm{~h}$ before examination by fluorescence microscopy. Images were acquired using an Olympus BX-51 inverted fluorescence microscope (Olympus, Japan). The image data were processed using Adobe Photoshop (Mountain View, CA, USA). All of the transient expression assays were repeated at least three times.

\section{In silico Promoter Analysis}

The cis-elements presented in the $1 \mathrm{~kb}$ region upstream of the translation start site of the strawberry $H s f$ genes were obtained from the PlantCARE database (Rombauts et al., 1999), and the corresponding nucleotide sequences were retrieved from NCBI with their gene IDs (http://www.ncbi.nlm.nih.gov/).

\section{Plant Materials and Treatments}

The wild diploid strawberry F. vesca accession Heilongjiang-3 was grown in the strawberry germplasm resource greenhouse of Northwest A\&F University. The potted strawberry plants were grown at $22^{\circ} \mathrm{C}$ with $70 \%$ relative humidity and no supplemental light. Six-month-old strawberry seedlings with the tenth leaf fully expanded were selected for treatments. The roots, stems, leaves, flowers, receptacles, and fruits of greenhousegrown Heilongjiang-3 were used to analyze the organ-specific expression of the FvHsf genes. A. thaliana ecotype Col-0 was grown at $22^{\circ} \mathrm{C}$ with $75 \%$ relative humidity under short-day $(8 \mathrm{~h}$ light at $125 \mu \mathrm{mol} \cdot \mathrm{m}^{-2} \cdot \mathrm{s}^{-1}, 16 \mathrm{~h}$ dark) conditions for $4-5$ weeks before transformation.

Heat stress treatment was performed by transferring potted strawberry plants to a $42^{\circ} \mathrm{C}$ chamber for $48 \mathrm{~h}$. Leaves were collected from the plants at $0,0.5,2,4,8,12,24$, and $48 \mathrm{~h}$ post-treatment (hpt). Cold stress treatment was performed by transferring the plants to a $4{ }^{\circ} \mathrm{C}$ chamber for $48 \mathrm{~h}$. Leaves were harvested from the plants at $0,0.5,2,4,8,12,24$, and $48 \mathrm{hpt}$. For both the heat and cold treatments, another set of potted Heilongjiang-3 seedlings were kept in the control temperature range of $22-27^{\circ} \mathrm{C}$. Salt stress was simulated by irrigating potted strawberry plants with $300 \mathrm{mM} \mathrm{NaCl}$ once. Another set of control Heilongjiang-3 seedlings was similarly treated with distilled water. The leaves were collected from the plants at $0,0.5$, $2,4,8,12,24$, and $48 \mathrm{hpt}$. Drought stress was simulated by withholding water and sampling at $0,24,48,72,96,120$, and $144 \mathrm{hpt}$. The plants were rewatered after $144 \mathrm{~h}$ of drought stress and sampled again $24 \mathrm{~h}$ later. The plants were inoculated with powdery mildew (Podosphaera aphanis) by touching the adaxial epidermis of Heilongiiang-3 with sporulating colonies located on the leaf surface of the strawberry cv. Red cheeks. Another set of control Heilongjiang-3 seedlings was similarly touched with uninfected, healthy leaves. The treated plants were then incubated in a controlled environment. Inoculated leaves were collected at $0,24,48,72,96,120,144$, and $168 \mathrm{~h}$ post-inoculation (hpi). The inoculations were repeated three times. For hormone treatments, the strawberry leaves were sprayed with a solution containing $0.1 \mathrm{mM}$ abscisic acid (ABA), $1 \mathrm{mM}$ salicylic acid (SA), $0.1 \mathrm{mM}$ methyl jasmonate (MeJA), or $0.5 \mathrm{~g} / \mathrm{L}$ ethephon (Eth), while another set of control Heilongjiang-3 seedlings were similarly sprayed with distilled water. The treated leaves were then collected at $0,0.5,2,4,8,12,24$, and $48 \mathrm{hpt}$ for RNA isolation. Six leaves from six separate plants were collected at each time point of each treatment and combined to form one sample, and all of the experiments were performed independently in triplicate.

\section{Semi-quantitative PCR and Real-time Quantitative PCR Analysis}

Total RNA was isolated from treated leaves or tissue samples using an EZNA Plant RNA Kit (R6827-01, Omega Bio-tek, USA). cDNA synthesis was performed using PrimeScript RTase (TaKaRa Biotechnology, Dalian, China). The strawberry $18 \mathrm{~S}$ gene was used as a control to normalize the amount of cDNA used from each sample (Raab et al., 2006). VECTOR NTI was used to design gene-specific primers for each FvHsf gene (Supplementary Table S1). The following semiquantitative reverse-transcription PCR program was used: $95^{\circ} \mathrm{C}$ for $3 \mathrm{~min}, 30-32$ cycles of $95^{\circ} \mathrm{C}$ for $30 \mathrm{~s}, 60^{\circ} \mathrm{C}$ for $30 \mathrm{~s}$ and $72^{\circ} \mathrm{C}$ for $30 \mathrm{~s}$, and a final step of $72^{\circ} \mathrm{C}$ for $5 \mathrm{~min}$. The PCR products were separated on a $1.0 \%(\mathrm{w} / \mathrm{v})$ agarose gel, stained with ethidium bromide, and imaged under UV light for further gene expression analysis. Each reaction was performed in triplicate, with the three independent analyses for each treatment showing the same trends for each gene. The expression profiles from the semi-quantitative RT-PCR were collated, analyzed, and visualized using the GeneSnap and $\mathrm{MeV}$ 4.8.1 programs.

Real-time quantitative PCR was carried out using SYBR green (TaKaRa Biotechnology) on an IQ5 real time-PCR machine (BioRad, Hercules, CA, USA) with a final volume of $21 \mu \mathrm{l}$ per reaction. Each reaction mixture contained $10.5 \mu$ l SYBR Premix Ex Taq II (TaKaRa Biotechnology), $1.0 \mu \mathrm{l}$ cDNA template, $1.0 \mu \mathrm{l}$ of each primer $(1.0 \mu \mathrm{M})$, and $7 \mu \mathrm{l}$ sterile distilled $\mathrm{H}_{2} \mathrm{O}$. Each reaction was performed in triplicate. The cycling parameters were 
$95^{\circ} \mathrm{C}$ for $30 \mathrm{~s}, 40$ cycles at $95^{\circ} \mathrm{C}$ for $30 \mathrm{~s}$ and $58^{\circ} \mathrm{C}$ for $30 \mathrm{~s}$. After amplification, the samples were kept at $50^{\circ} \mathrm{C}$ for $1 \mathrm{~min}$ and the temperature was gradually raised by $0.5^{\circ} \mathrm{C}$ every $10 \mathrm{~s}$ to perform the melt-curve analysis. Relative gene expression was determined using an 18S-26S interspacer gene as an endogenous control gene (Raab et al., 2006). Each relative expression level was analyzed with IQ5 software using the Normalized Expression method. The primers used for real-time RT-qPCR are listed in Supplementary Table S1.

\section{Statistical Analysis}

The data are presented as the mean \pm standard deviation of the mean (SD) and were tested for statistical significance with a paired Student's $t$-test (http://www.physics.csbsju.edu/stats/). $p<0.05$ was selected as the point of minimal statistical significance in all of the analyses.

\section{Results}

\section{Identification and Isolation of Hsf Genes in the Diploid Strawberry}

A total of 17 strawberry $H s f$ genes were originally obtained through the BLAST search in NCBI using the 15 strawberry Hsf amino acid sequences that were predicted in the sequenced genome of the accession Hawaii-4 (http://planttfdb.cbi.pku.edu.cn/) (Shulaev et al., 2011). All 17 of the proteins contained apparently complete Hsf-type DNA-binding domains (PF00447) and oligomerization domains (Never et al., 1996; Scharf et al., 2012). As a result, 17 FvHsf members were identified in the diploid strawberry (Table 1). More detailed information about each FvHsf gene, including the Hsf gene IDs, gene location, length of the coding sequences, and the characteristics of the FvHsf proteins can be found in Table 1. Using the predicted FvHsf coding sequences, we initially isolated 14 homologous genes from a diploid woodland strawberry accession Heilongjiang-3 (F. vesca). It is notable that the ORF sequences of the isolated $F v H s f s$ from accession Heilongjiang-3 share high identities ( $\geq 96 \%, E$-value $=0)$ with the corresponding $F v H s f s$ in strawberry accession Hawaii-4 (Shulaev et al., 2011) (Table 1).

\section{Phylogenetic Analysis and Classification of FvHsf Proteins}

Compared with fungi and animals, plants possess large numbers of Hsf genes (Von Koskull-Doring et al., 2007), and the plant Hsf genes were assigned into A, B, and C classes based on the diversity of the oligomerization domain (Never et al., 1996). To examine the classification of FvHsf members and to gain some insight into the potential function of FvHsf proteins from well-studied Hsfs in other plant species, we used fulllength amino acid sequences to perform a phylogenetic analysis of Hsf proteins from strawberry, rice, apple, grapevine, and Arabidopsis (Figure 1A). The phylogenetic analysis indicated that the $106 \mathrm{Hsf}$ proteins from these plants were clearly grouped into three different clades corresponding to the Hsf classes A, B, and C (Figure 1A, Table 1, and Supplementary Table S2). Within each Hsf protein class, particular clusters of orthologous and paralogous genes have been identified, showing ancestral

TABLE 1 | Characteristics of strawberry Hsf genes.

\begin{tabular}{|c|c|c|c|c|c|c|c|c|}
\hline Name & Gene ID ${ }^{a}$ & Gene location & $\begin{array}{l}\text { Length } \\
\text { (bp) }\end{array}$ & $\begin{array}{c}\text { Number } \\
\text { of aa }\end{array}$ & $\begin{array}{l}M^{\mathbf{b}} \\
(k D a)\end{array}$ & $\begin{array}{l}\text { Isoelectric } \\
\text { point }^{b}\end{array}$ & $\begin{array}{l}\text { Identity/ } \\
\text { E-value }\end{array}$ & $\begin{array}{l}\text { Accession } \\
\text { numbers }^{d}\end{array}$ \\
\hline FVHsfA1b & 101302336 & LG3: 11614311-11618187 & 3876 & 494 & 55.01 & 5.02 & $99 \%, 0.0$ & KT283219 \\
\hline FvHsfA1d & 101302657 & LG5:21020179-21025194 & 5015 & 508 & 55.66 & 4.80 & $99 \%, 0.0$ & KT283220 \\
\hline FvHsfA2a & 101312795 & LG2:20570433-20572945 & 2512 & 372 & 41.97 & 4.86 & $99 \%, 0.0$ & KT283221 \\
\hline FvHsfAЗa & 101295258 & LG6:13129046-13132026 & 2980 & 456 & 50.35 & 4.77 & $99 \%, 0.0$ & KT283222 \\
\hline FvHsfA4a & 101311435 & LGun:147013-149497 & 2484 & 497 & 55.72 & 5.13 & $99 \%, 0.0$ & KT283223 \\
\hline FvHsfA4b & 101290970 & LG6:16216378-16219992 & 3614 & 439 & 49.77 & 4.99 & - & - \\
\hline FvHsfA5a & 101302160 & LG4:14062542-14066187 & 3645 & 578 & 64.93 & 7.40 & $99 \%, 0.0$ & KT283224 \\
\hline FvHsfA6a & 101307359 & LG2:16115738-16118875 & 3137 & 362 & 41.18 & 5.79 & $99 \%, 0.0$ & KT283225 \\
\hline FvHsfA7a & 101297339 & LG4:5513754-5515879 & 2125 & 345 & 40.13 & 5.42 & - & - \\
\hline FvHsfA8a & 101290755 & LG4:19035204-19038162 & 2958 & 474 & 54.45 & 4.99 & - & - \\
\hline FvHsfA9a & 101302973 & LG1:6313891-6316458 & 2567 & 447 & 50.90 & 5.23 & $99 \%, 0.0$ & KT283226 \\
\hline FvHsfB1a & 101294882 & LG1:10956423-10958906 & 2483 & 290 & 32.01 & 5.96 & $99 \%, 0.0$ & KT283227 \\
\hline FvHsfB2a & 101299242 & LG7:22683186-22684501 & 1315 & 289 & 31.97 & 8.82 & $98 \%, 0.0$ & KT283228 \\
\hline FvHsfB2b & 101301205 & LG5:1089695-1092781 & 3086 & 355 & 38.41 & 4.79 & $96 \%, 0.0$ & KT283229 \\
\hline FvHsfB3a & 101307517 & LG6:33122976-33124719 & 1743 & 236 & 27.10 & 5.91 & $99 \%, 0.0$ & KT283230 \\
\hline FvHsfB4a & 101301353 & LG2:21014849-21016923 & 2074 & 386 & 43.21 & 7.73 & $99 \%, 0.0$ & KT283231 \\
\hline FvHsfC1a & 101304412 & LG1:3848442-3850066 & 1624 & 362 & 40.49 & 5.77 & $99 \%, 0.0$ & KT283232 \\
\hline
\end{tabular}

aIDs are available in the strawberry Genome Database (http://www.rosaceae.org).

${ }^{b}$ Detailed FvHsf protein characteristics were predicted by ExPASy online service (http://web.expasy.org/cgi-bin/compute_pi/pi_tool).

${ }^{c}$ The identities of the isolated FvHsf genes were derived from a NCBI Blast search using the FvHsf Heilongjiang-3 nucleotide sequences.

'Sequence data of isolated FvHsfs can be found in GenBank databases using these accession numbers. 

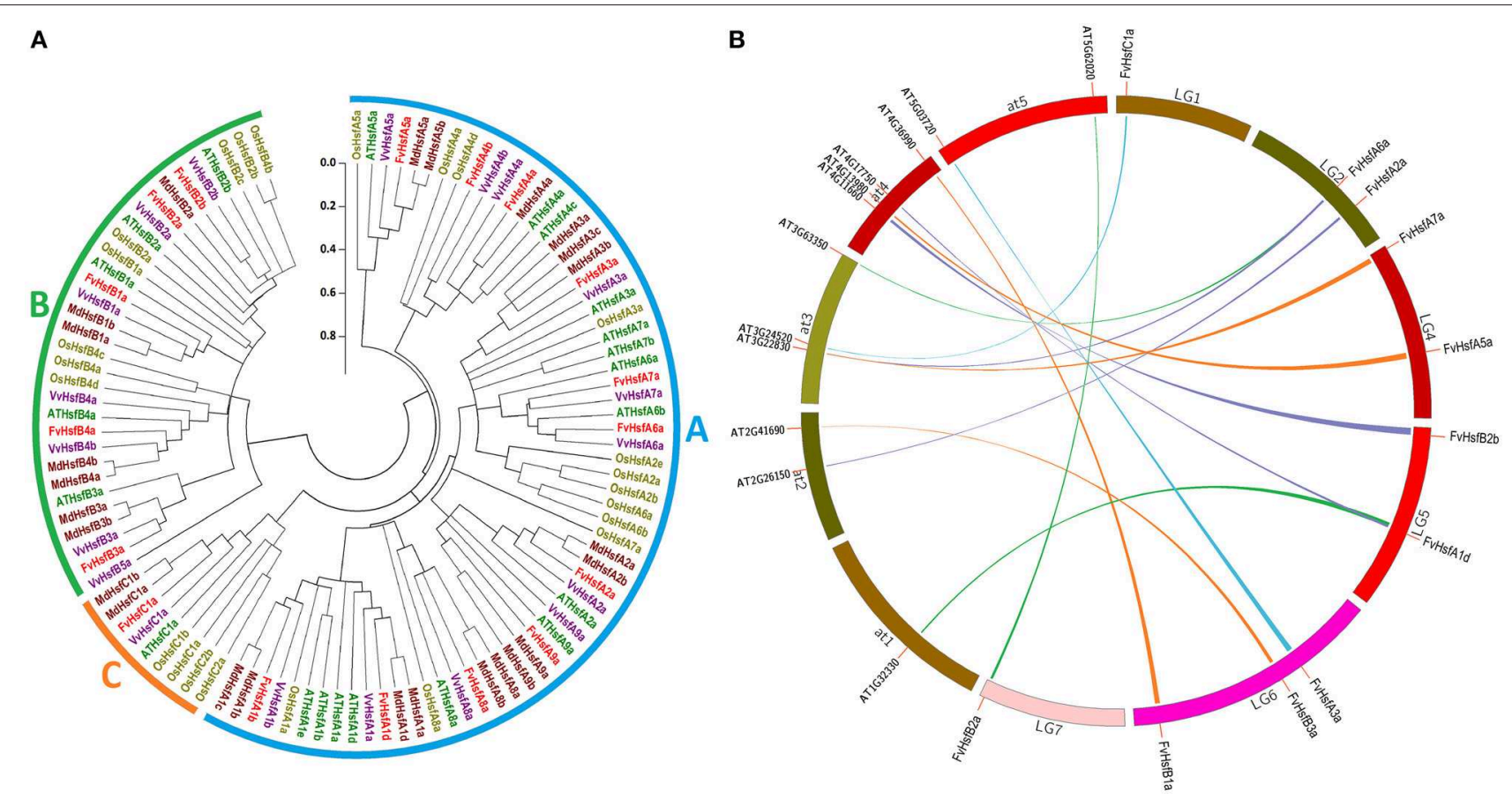

FIGURE 1 | Comparative analysis of strawberry Hsf genes with the corresponding genes in rice, apple, grapevine, and Arabidopsis. (A) The linearized neighbor-joining phylogenetic tree of Hsf proteins from strawberry, rice, apple, grapevine, and Arabidopsis. The full-length amino acid sequences of the Hsf proteins were used to construct the phylogenetic tree using the MEGA 5.0 program. Unrooted neighbor-joining analysis was performed with pairwise deletion and the Jones-Taylor-Thornton (JTT) model. The filled circle lines were used to cluster the genes into the A, B, and C classes. (B) Synteny analysis of strawberry and Arabidopsis Hsf genes. The strawberry and Arabidopsis chromosomes are depicted as a circle. The approximate location of each AtHsf and FvHsf gene is marked with a short red line on the circle. The colored curves denote the syntenic regions of the strawberry and Arabidopsis Hsf genes.

speciation or duplication events. For example, the monocot rice has an additional C2 clade but has lost the A9 and B3 clades (Figure 1A). Although all of the clades resolved in dicots (apple, grapevine, and Arabidopsis) are represented in the strawberry Hsf proteins, fewer paralogous pairs may limit the size of the FvHsf family (Figure 1A).

\section{Syntenic Relations, Exon-Intron Organization, and Protein Domains of the FvHsf Genes}

Most of the Arabidopsis Hsf genes have been systematically investigated in recent years, and a synteny analysis of strawberry Hsfs and Arabidopsis Hsfs was performed in the present work to ascertain whether this information might provide more functional insight. A total of 11 pairs of syntenic Hsf genes were found between strawberry and Arabidopsis; this number included 11 FvHsf genes and 12 AtHsf genes (Supplementary Table S3; Figure 1B). Interestingly, two FvHsf genes (FvHsfA1d, FvHsfA6a) and one AtHsf gene (AtHsfA6b) were found to be associated with two syntenic blocks (Supplementary Table S3). Insights into the structure of the FvHsf genes were obtained through an analysis of the exon/intron boundaries, which are known to play key roles in gene family evolution (Schwartz et al., 2009). As shown in Figure 2, the FvHsf genes exhibit a highly conserved exon-intron organization: of the $17 \mathrm{FvHsf}$ genes, 14 possess two exons and three have one exon. It is interesting that the introns of the
FvHsf genes divide the highly conserved DNA-binding domains coding regions into two parts, and all of the introns are phase zero introns. Plant Hsf proteins show a highly modular assembly of protein domains (Never et al., 1996; Scharf et al., 2012). We used the online MEME tool to predict the conserved FvHsf protein domains, identifying 23 conserved motifs (Figure 2; Supplementary Table S2). Unsurprisingly, all 17 of the FvHsfs showed the presence of a DNA-binding domain (DBD) in the Nterminal of the protein (Figure 2; Supplementary Table S2). The oligomerization domains (OD or HR-A/B region), which differ in sequence among the class $\mathrm{A}, \mathrm{B}$, and $\mathrm{C}$ members, are adjacent to the DBD (Figure 2; Supplementary Table S2). In addition, nuclear localization signal (NLS) motifs were found in 15 FvHsfs, nuclear export signal (NES) motifs were found in five class A FvHsfs, and transcription activator (AHA) motifs were found in eight class A FvHsfs (Figure 2; Supplementary Table S2). Overall, each FvHsf protein contained the necessary DBD and OD, but some FvHsfs have specific motifs such as NLS, NES, and/or AHA, which might lay the foundation for the functional divergences between different FvHsfs (Scharf et al., 1998; Döring et al., 2000; Heerklotz et al., 2001).

\section{Regulatory Elements in the FvHsf Promoters}

An in silico survey of the putative cis-elements in the $1 \mathrm{~kb}$ region upstream of the translation initiation codon of various FvHsf genes showed the presence of some abiotic stress 


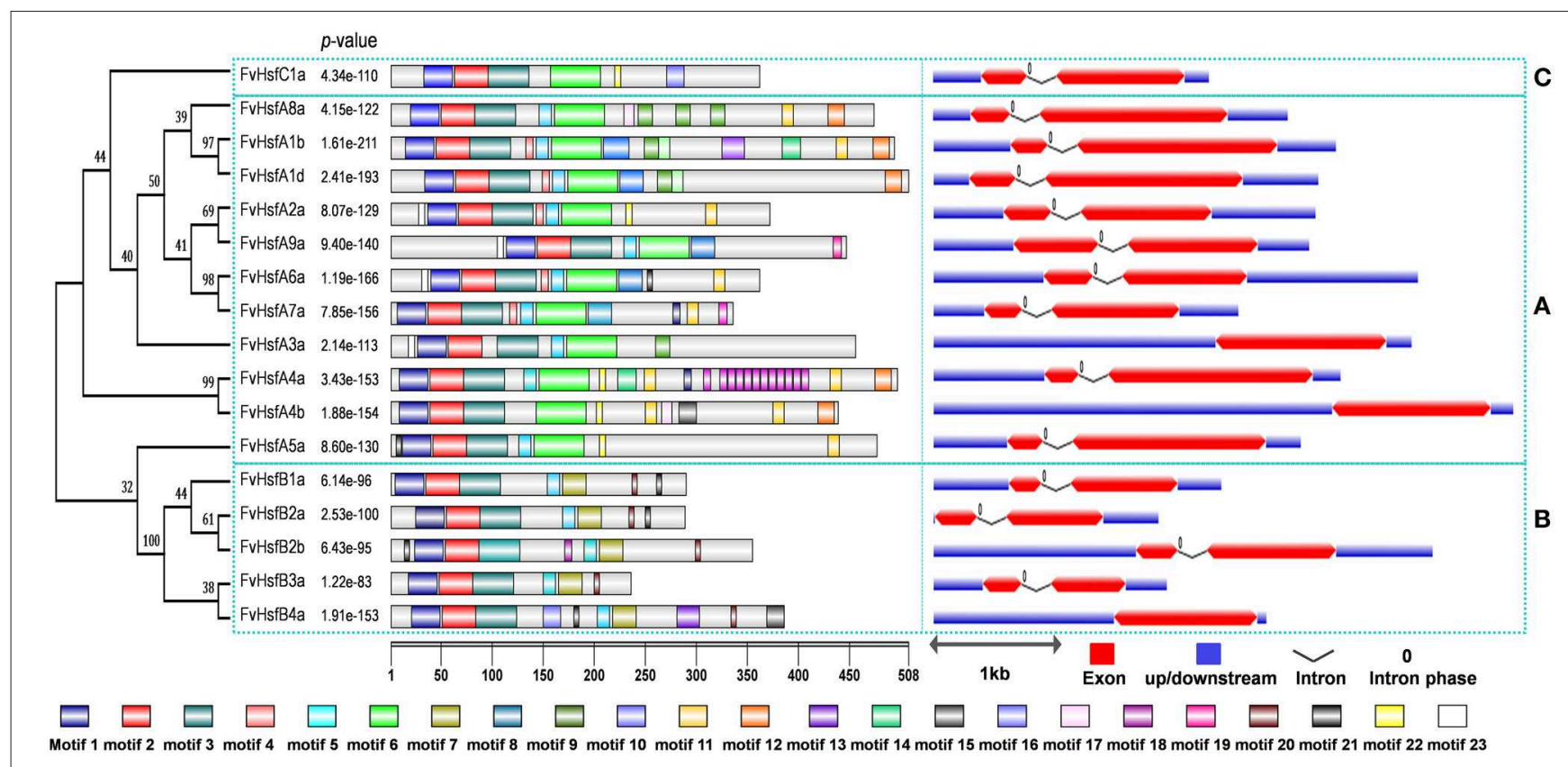

FIGURE 2 | Structural analysis of strawberry Hsf genes. The protein domains of the strawberry Hsf genes are shown on the left and are denoted by rectangles with different colors. The exon-intron organization is shown on the right, with exons and introns represented by red wedges and black lines, respectively, and untranslated regions (UTRs) indicated by blue boxes. The number 0 represents the intron phase. The exon size can be estimated using the scale at the bottom of the diagram, while all of the introns were set to same length. The blue dashed rectangles are used to cluster the genes into the A, B, and C classes.

response elements such as HSEs (heat shock elements), which were found in FvHsfA2a, FvHsfA4a, FvHsfA6a, FvHsfB2a, and FvHsfCla (Figure 3). In addition, LTR, a cis-acting element involved in low-temperature responsiveness (Jiang et al., 1996) was observed in FvHsfAlb, FvHsfA4a, and FvHsfA8a; anoxia responsive elements (ARE) were observed in 13 FvHsf genes; MBS (MYB binding site), a cis-acting element involved in drought-inducibility (Deng et al., 1996), was found in 10 FvHsf genes; Box-W1, a fungal elicitor responsive element, was identified in FvHsfA5a, FvHsfA9a, and FvHsfB2a; and TCrich repeats, a cis-acting element involved in defense and stress responsiveness, was seen in 11 FvHsf genes. Lastly, ABA responsive elements (ABREs) were found in nine $F v H s f$ genes, MeJA responsive elements (CGTCA-motif/TGACG-motif) were observed in eight $F v H s f$ genes, and SA responsive elements (TCA-element) were seen in nine FvHsf genes (Figure 3). Notably, plenty of hormone-responsive elements were seen in the FvHsf promoter sequences, indicating that phytohormones could play central roles in regulation of heat stress responses (Clarke et al., 2009).

\section{Subcellular Localization of FvHsfs}

The cellular localization of Hsfs is essential to their functions (Scharf et al., 1998). To investigate the subcellular localization of FvHsfs, the coding-sequences of $14 \mathrm{FvHsf}$ genes were fused in-frame with GFP under control of the CaMV $35 S$ promoter. The fusion constructs and the positive control were transiently expressed in Arabidopsis mesophyll protoplasts. As shown in Figure 4, the GFP expressed from the control construct was dispersed throughout the whole cell, whereas the most of the FvHsf fusion proteins were clearly located in the nucleus. However, some of the FvHsf fusion proteins, including FvHsfA2a-GFP, FvHsfA3a-GFP, FvHsfA4a-GFP, FvHsfA5a-GFP, FvHsfB2b-GFP, and FvHsfC1a-GFP, were also detected in the cytosol. To confirm the nuclear and cytosolic localization of the FvHsfs, we also examined the subcellular localization of VpCDPK2, a grape calcium-dependent protein kinase that was reported to localize to both the nucleus and cytosol of Arabidopsis mesophyll protoplasts (Zhang et al., 2015). The FvHsfs and VpCDPK2 exhibited similar subcellular distributions (Figure 4). These results might have broader implications for understanding the subcellular localization of plant Hsfs (Lyck et al., 1997; Kotak et al., 2004).

\section{Expression Profiles of FvHsfs in Different Organs of the Strawberry Plant}

To determine the biological roles of $H s f$ genes in strawberry Heilongjiang-3, the distribution of 17 FvHsfs transcripts was surveyed in six major organs (roots, stems, leaves, flowers, receptacles, and fruits) under non-stress conditions. As shown in Figure 5B, the $F v H s f A 1 d, F v H s f A 2 a$, and $F v H s f B 3 a$ transcripts showed consistent distribution throughout all of the tested organs, and most of the FvHsf genes exhibited high mRNA levels in the fruits of Heilongjiang-3, with the exception of $F v H s f B 2 a$ and FvHsfCla. The FvHsfA1b, FvHsfA4b, FvHsfA5a, FvHsfB1a, $F v H s f B 2 b$, and $F v H s f C 1 a$ genes showed high transcription levels in the flowers and receptacles of Heilongjiang-3; FvHsfAlb, FvHsfA3a, FvHsfA4a, FvHsfA6a, and FvHsfCla also exhibited 
$5^{\prime}-1000 b p---$

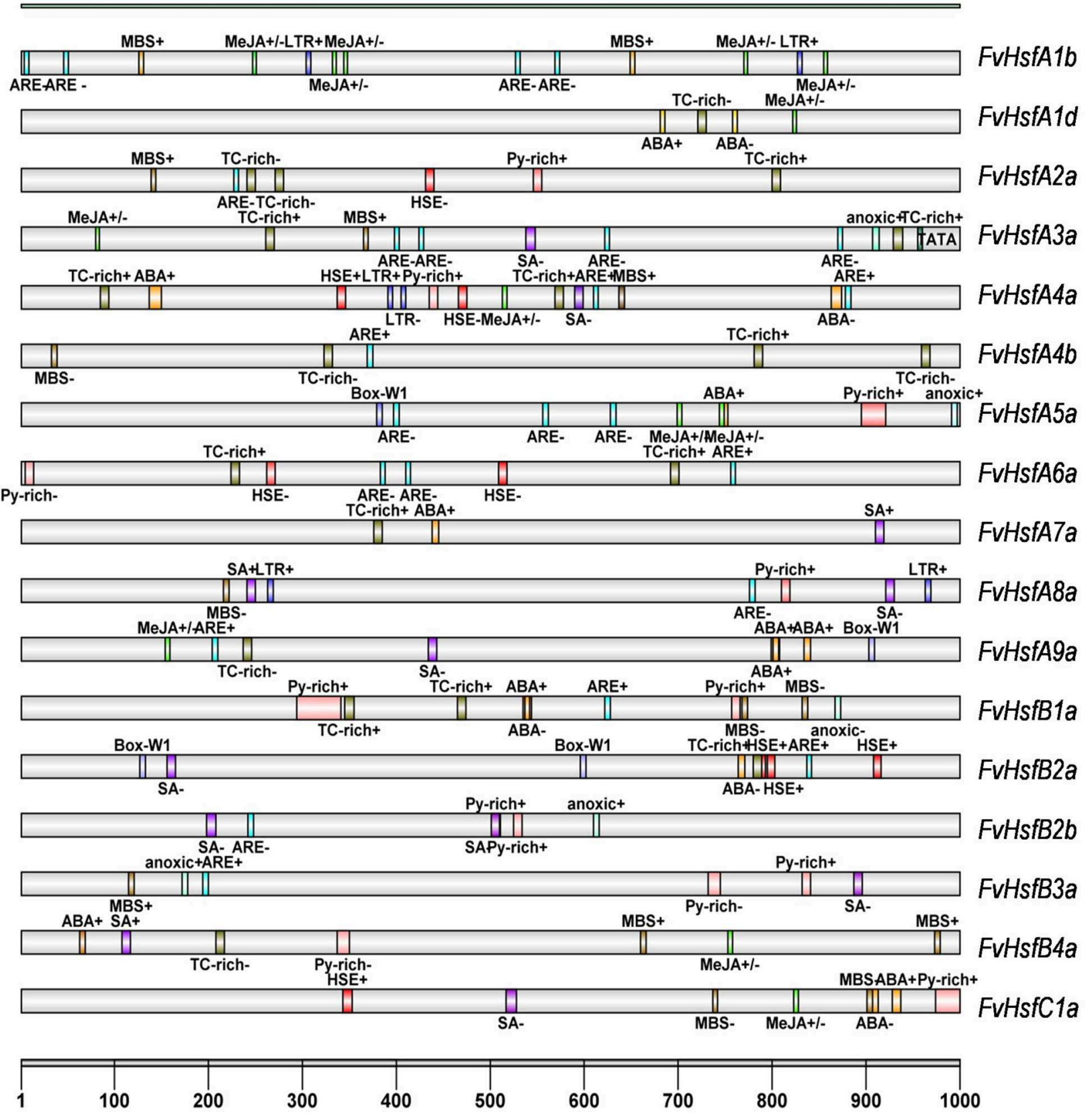

FIGURE 3 | Cis-elements are present in the $\mathbf{1} \mathbf{k b}$ region upstream of the strawberry Hsf translation start site. The analysis was performed using the PlantCARE database. The different-colored boxes mark the relative positions of the different elements.

higher transcript abundance in old leaves than in roots, stems, and young leaves. In addition, the FvHsfAlb, FvHsfA4b, FvHsfA5a, FvHsfA8a, FvHsfA9a, and FvHsfB1a transcripts could not be detected in the roots of Heilongjiang-3, while FvHsfB2a could not be detected in any Heilongjiang-3 tissues. The organspecific FvHsf expression patterns suggest that FvHsfs could play important biological roles in the growth and development of strawberries (Kotak et al., 2007).

\section{FvHsfs Act as Positive Responders to Heat Stress in Strawberry}

To understand how $H s f$ genes respond to heat stress in strawberry, we exposed Heilongjiang- 3 to $42^{\circ} \mathrm{C}$ conditions and performed semi-quantitative RT-PCR to determine expression profiles for the FvHsf gene family (Figure 5A and Supplementary Figure S1). Based on the results of the semiquantitative RT-PCR, we selected 15 characteristic FvHsfs using 


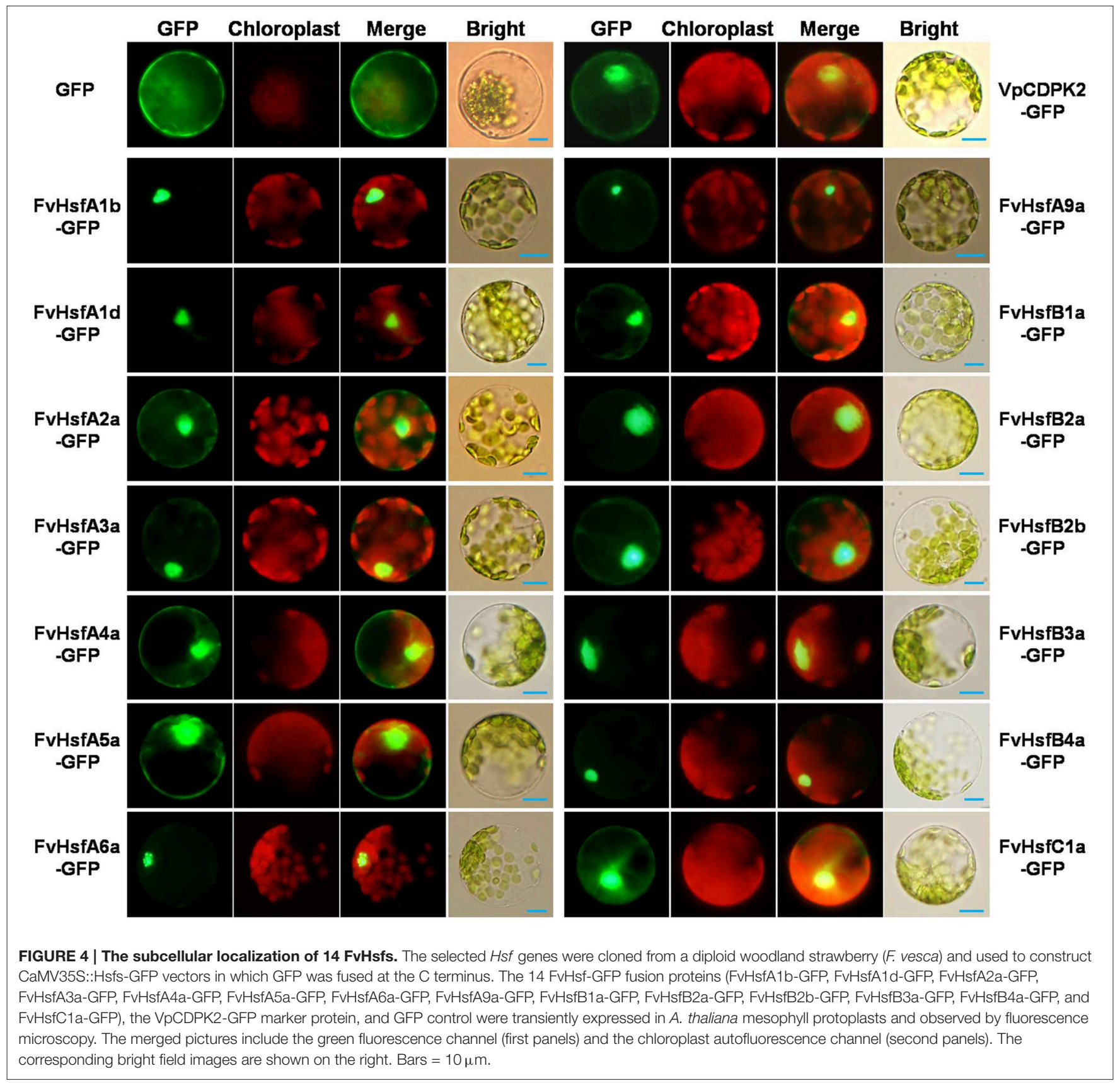

real-time quantitative RT-PCR to further test their transcript abundance during $42^{\circ} \mathrm{C}$ treatment (Figure 6).

As shown in Figure 6, the $15 \mathrm{FvHsf}$ genes showed distinct expression patterns during $42^{\circ} \mathrm{C}$ treatment. Of the $15 \mathrm{FvHsfs}$, FvHsfA2a was the most strongly heat stress induced $H s f$ gene in strawberry, reaching its highest transcription level $(\sim 600$ fold) at 0.5 hpt. FvHsfA3a, FvHsfA6a, and FvHsfB1a were also strongly induced at $0.5 \mathrm{hpt}$, maintaining elevated mRNA levels ( $\sim 10$ - to 200 -fold) throughout the entire treatment period. FvHsfA1d, FvHsfA9a, and FvHsfCla were highly induced at the late stage (24-48 hpt) of $42^{\circ} \mathrm{C}$ treatment, with these transcripts up-regulated 6- to 40 -fold during this time period. FvHsfA5a,
$F v H s f B 2 a$, and $F v H s f B 2 b$ were up-regulated in the earlier stage of treatment $(0.5-2 \mathrm{hpt})$, but returned to baseline or were down-regulated after 2 hpt. FvHsfA4a, FvHsfA4b, FvHsfA7a, and $F v H s f A 8 a$ were primarily down-regulated in response to treatment, but FvHsfA7a and FvHsfA8a returned to baseline at the late stage of treatment. FvHsfAlb was only slightly upregulated at 2 and $48 \mathrm{hpt}$.

\section{FvHsfs are Associated with Other Abiotic and Biotic Stresses in Strawberry}

Although $H s f s$ are primarily involved in heat acclimatization, these genes have also been reported to play roles in plant 
A

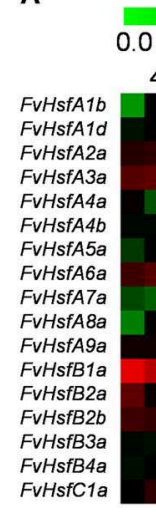

0.0

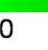

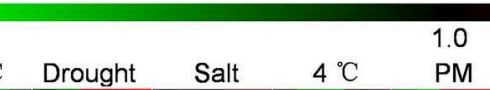

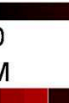
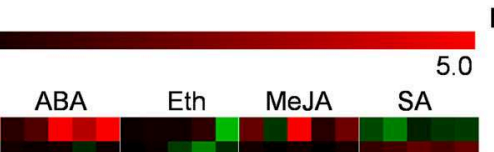

.

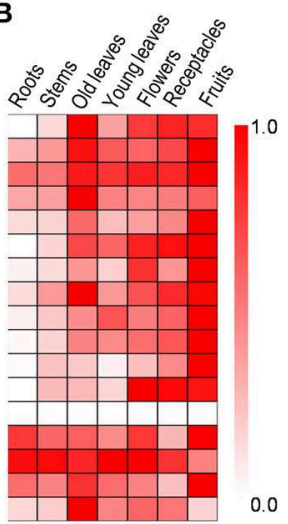

FIGURE 5 | The expression pattern of 17 FvHsf genes in different organs/tissues and under different treatments. The expression profiles were generated by semi-quantitative PCR and were visualized as heat maps. The color scale represents log2 expression values, with red denoting increased transcript abundance and green denoting decreased transcript abundance. Only partial data are shown for the stress and hormone treatments (the expression levels of 17 FvHsfs at $0.5 \mathrm{hpt}, 2 \mathrm{hpt}, 4 \mathrm{hpt}, 24 \mathrm{hpt}$, and $48 \mathrm{hpt}$ of heat, cold, salt, and hormone treatments; the expression levels of 17 FvHsfs at 24 hpt/i, $48 \mathrm{hpt} / \mathrm{i}, 72 \mathrm{hpt} / \mathrm{i}, 144 \mathrm{hpt} / \mathrm{i}$, and $168 \mathrm{hpt} / \mathrm{i}$ of drought treatment and powdery mildew infection). Detailed expression profiles of all 17 FvHsfs in response to all treatments are provided in Supplementary Figures S1, S2. (A) The expression profiles of the $17 \mathrm{FvHsfs}$ in response to different treatments. (B) The organ/tissue distribution of 17 FvHsf genes under homeostatic conditions, with the red marks indicating the relative level of each FvHsf transcript in different organs/tissues.

adaptations to other environmental stresses, including cold (Mittal et al., 2009), salt (Hwang et al., 2014), drought (PrietoDapena et al., 2008; Hwang et al., 2014) and pathogen infection (Pick et al., 2012). In this study, the semi-quantitative RTPCR indicated that most of the FvHsfs (FvHsfA1b, A2a, A3a, $A 4 a, A 5 a, A 6 a, A 8 a, A 9 a, B 1 a, B 2 a, B 2 b, B 4 a$, and $C 1 a)$ showed detectable changes at the transcript level when strawberry plants were exposed to specific stress conditions (Figure 5A; Supplementary Figures S1, S2). These data suggest that these FvHsfs are involved in the response to almost all stress treatments, but examination with real-time quantitative RT-PCR revealed that the expression of each FvHsf is highly specific (Figures 7, 8).

FvHsfA3a and FvHsfA4a were up-regulated 3- and 10fold, respectively, during the $2-8 \mathrm{hpt}$ period after $4^{\circ} \mathrm{C}$ treatment, whereas FvHsfA9a was up-regulated over 3-fold during the 24-48 hpt period of the same treatment (Figure 7A). FvHsfA3a was highly up-regulated 24-96 hpt after drought treatment, whereas FvHsfA4a, FvHsfB1a, and FvHsfCla were initially up-regulated within 48 hpt and FvHsfA4a, FvHsfA5a, FvHsfA9a, FvHsfB1a, and FvHsfCla were highly induced 96 hpt (Figure 7B). The FvHsfA4a, FvHsfA5a, FvHsfA9a, and $F v H s f C 1 a$ transcripts returned to baseline or decreased when the plants were rewatered, but $F v H s f B 1 a$ remained up-regulated 11 -fold at this time point (Figure 7B). In addition, the FvHsfA2a transcript was up-regulated in the earlier stage of salt stress treatment before decreasing to its lowest level at $12 \mathrm{hpt}$ (Figure 5A; Supplementary Figure S1). In contrast, the FvHsfA3a, FvHsfA5a, FvHsfA9a, and FvHsfB1a transcripts were primarily up-regulated at the middle or late stage of salt treatment. The level of the FvHsfC1a transcript first increased and then decreased during salt treatment (Figure 7C). After inoculation with Podosphaera aphanis, FvHsfBla levels gradually increased during the earlier stage (24-96 hpi) and dramatically increased $120 \mathrm{hpi}$, whereas $F v H s f A 1 b$ and FvHsfA3a were clearly down-regulated during the earlier stage (Figure 7D).

\section{FvHsf Expression in Response to Hormone Treatments}

Phytohormones such as abscisic acid (ABA), ethylene (Eth), salicylic acid (SA), and jasmonic acid (MeJA) have wellestablished roles in plant stress signaling networks (Kotak et al., 2007a; Clarke et al., 2009). To assess the potential roles of FvHsfs in phytohormone-mediated signal transduction, we examined the transcriptional abundance of 17 FvHsfs during ABA, Eth (ethephon), SA, and MeJA (Methyl jasmonate) treatments. Quantitative RT-PCR analysis revealed that ABA treatment causes the rapid $(0.5 \mathrm{hpt})$ up-regulation of several $F v H s f$ genes, including FvHsfA2a, FvHsfA5a, FvHsfA6a, FvHsfB1a, and FvHsfC1a. The levels of these transcripts remained higher (4to 125 -fold) throughout the entire treatment period (Figure 8). During Eth treatment, FvHsfA3a, FvHsfA5a, and FvHsfC1a were gradually up-regulated by 7.5 - to 12 -fold within $8 \mathrm{hpt}$, whereas FvHsfBla was only up-regulated at 4 and $12 \mathrm{hpt}$. Treatment with MeJA also increased FvHsfA4a, FvHsfA5a, FvHsfB1a, and FvHsfC1a levels significantly (6- to 70-fold) throughout the entire treatment period, while $\mathrm{FvHsfB2a}$ was only up-regulated at $2 \mathrm{hpt}$ before returning to a lower ( $\sim 0.5$-fold) abundance. During SA treatment, the FvHsfA4a, FvHsfA6a, FvHsfBla, and FvHsfCla transcripts exhibited a continuous increase: the transcript levels first peaked at 4 hpt and were again up-regulated during the 24-48 hpt

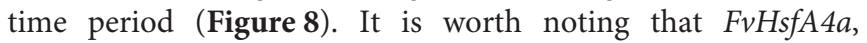
$F v H s f A 5 a, F v H s f A 6 a, F v H s f B 1 a$, and FvHsfC1a were clearly involved in the response to all four of the hormone treatments (Figures 5A, 8). 


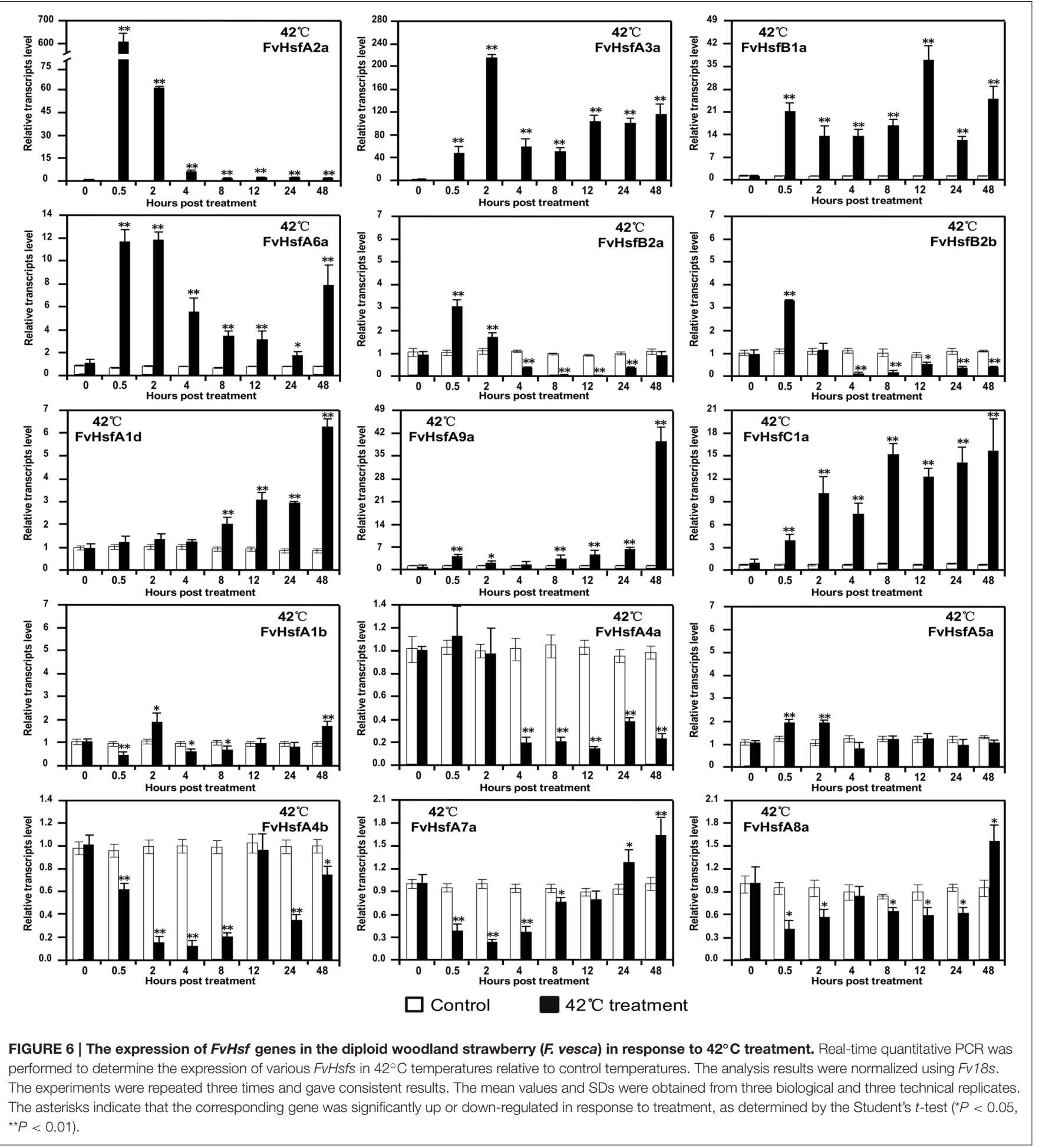

\section{Discussion}

F. vesca, a diploid woodland strawberry with a small and sequenced genome, is an excellent model for studying the counterparts of many important genes in the Rosaceae fruit crops (Shulaev et al., 2011; Darwish et al., 2015). An increasing amount of evidence has indicated that $H s f$ genes play essential roles in plant adaptations to various stress conditions (Shen et al., 2015; Xue et al., 2015). To explore Hsf functions in abiotic and biotic stress responses in the strawberry, this study identified and isolated $H s f$ genes in a diploid woodland strawberry in addition to analyzing the evolutionary relationships, gene structure, 


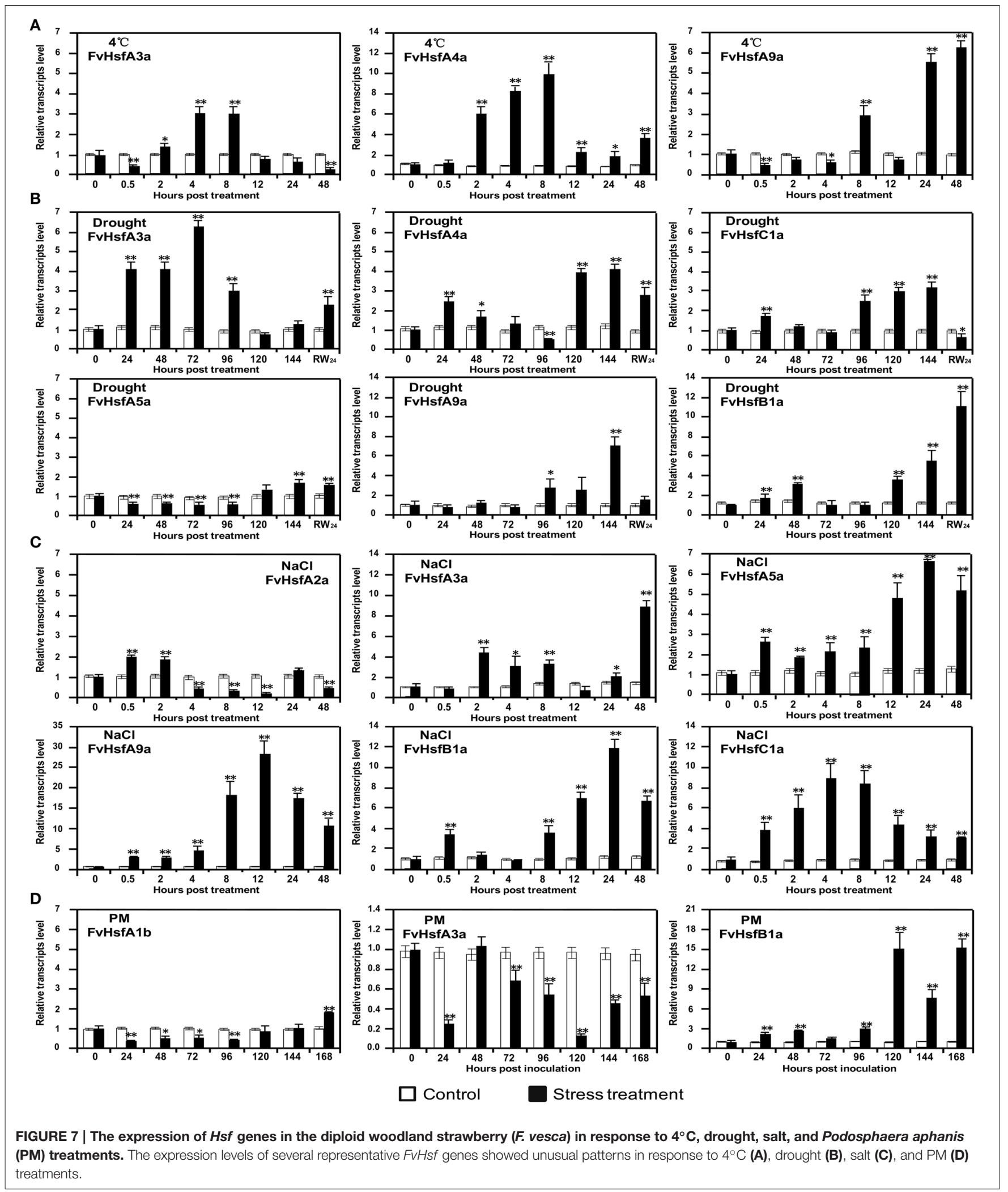

protein domains, subcellular localization, and expression profiles of these genes in response to abiotic or biotic stresses and hormone treatments.
The Hsf Gene Family is Conserved in Strawberry

The size of the strawberry Hsf gene family (17) is smaller than that of other plant species, such as Arabidopsis (21) 


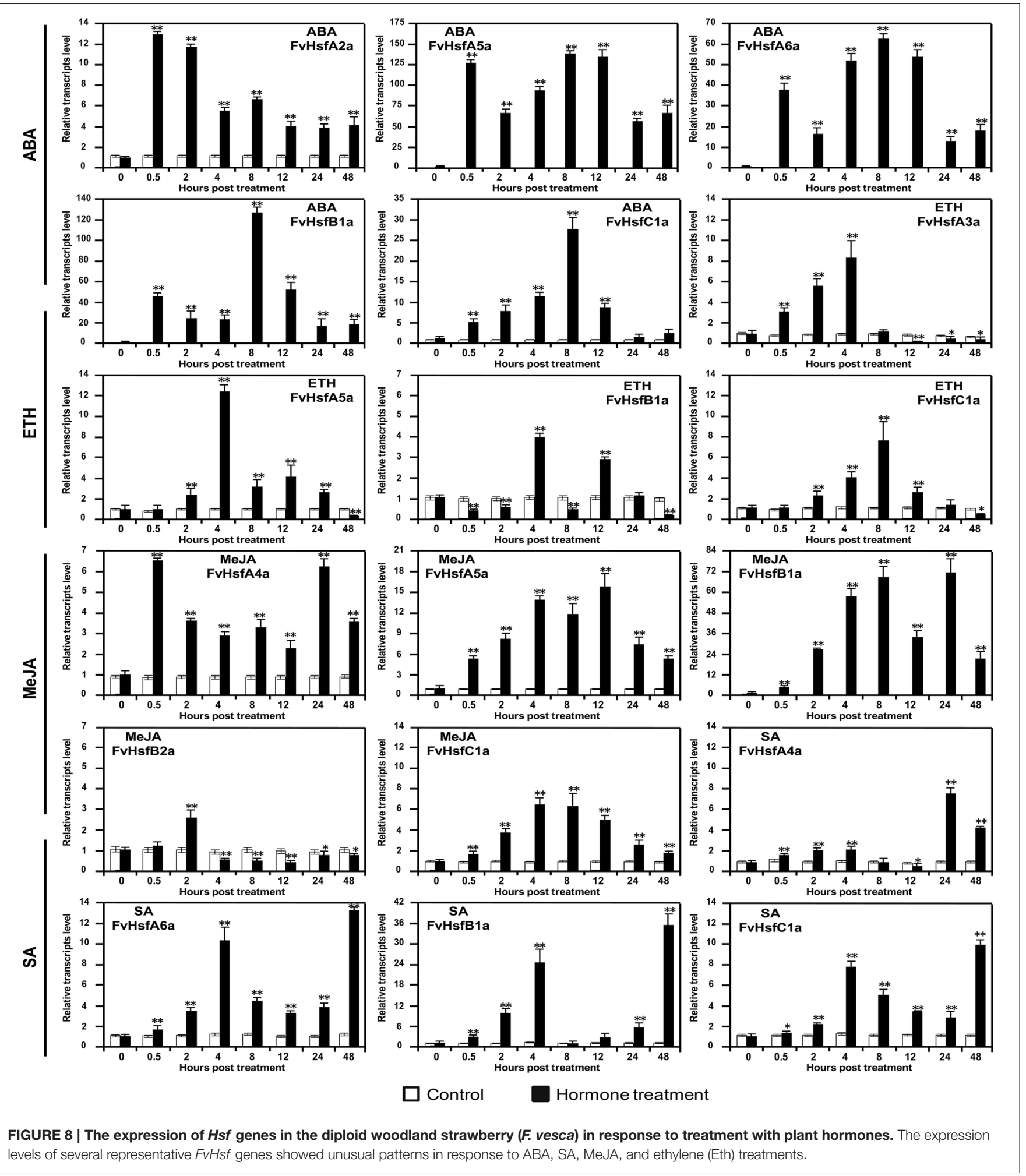

(Scharf et al., 2012), rice (25) (Guo et al., 2008), apple (25) (Giorno et al., 2012), wheat (56) (Xue et al., 2014), and soybean (59) (Chung et al., 2013). The small size of the strawberry genome (Shulaev et al., 2011; Darwish et al., 2015) and lack of the large genome duplications seen in apple (Velasco et al., 2010), soybean (Schmutz et al., 2010), and wheat (Mayer et al., 2014) could explain the limited size of the FvHsf family (Figure 1A). 
The comparative genomics approach structures genomes into syntenic blocks that exhibit conserved features (Ghiurcuta and Moret, 2014). This synteny analysis provided evolutionary and functional connections between genes in strawberry and Arabidopsis. Eleven strawberry $H s f$ genes were found to have syntenic relationships with Arabidopsis genes (Figure 1B), suggesting that most of the strawberry $H s f$ genes might have arisen before the divergence of the Arabidopsis and strawberry lineages. All of these FvHsf genes show close phylogenetic relationships with the corresponding AtHsf genes (Figure 1A), suggesting the potential for functional similarities. Structural characteristics such as intron-exon structures and protein domains might reflect the functional conservation or differentiation of the gene family. Fourteen of the seventeen FvHsf genes have only one phase zero intron while the others lack this intron (Figure 2), suggesting that the FvHsf gene family is conserved (de Souza et al., 1998). Besides, all 17 of the FvHsf proteins contain the necessary and/or specific protein domains (DBD, OD, NLS, NES, and AHA), which might be essential for functional conservation (Giorno et al., 2012). Fourteen of the FvHsf proteins retained the ability to localize in the nucleus, suggesting that most (14/17) of the FvHsf genes still maintain ancestral functional features (Figure 4).

\section{FvHsf Genes Could Play Essential Roles in Strawberry Adaptation to Abiotic or Biotic Stresses}

The function of plant Hsfs is to elicit the expression of genes encoding heat shock proteins (Hsps) or other stress-inducible genes (Schramm et al., 2006; Chan-Schaminet et al., 2009; Nishizawa-Yokoi et al., 2009) that are known to play a central role in protecting plants from heat or other stress conditions (Scharf et al., 2012). Recent genome-wide expression profile analyses of crop plants (rice, wheat, soybean, and apple) indicated that several $H s f$ genes are transcribed at high levels during heat, cold, salt, and drought stresses (Mittal et al., 2009; Giorno et al., 2012; Chung et al., 2013). In this study, 15 FvHsf genes showed distinct expression patterns during heat treatment (Figure 6), with most of these genes also were induced by other abiotic or biotic stresses and hormone stimuli (Figures 7, 8). It is notable that the subcellular localization of each FvHsf protein was different (Figure 4). All of our data suggest that the FvHsfs are involved in the response to almost all of the stress treatments, but these genes are highly specific in function.

FvHsfA2a, whose rice orthologs are OsHsfA2a/b/e, was found in the chromosomal region syntenic with AtHsfA2a (Figure 1). The characteristics of FvHsfA2a are highly consistent with the characteristics of OsHsfA2 and AtHsfA2a. For example, OsHsfA2a and $A t H s f A 2 a$ have been reported as the most strongly induced $H s f s$, accumulating to high levels in plants exposed to longterm heat stress (Schramm et al., 2006; Mittal et al., 2009). This finding is consistent with our results showing that FvHsfA2a was the most strongly induced of the 17 FvHsfs ( $\sim 600$-fold) in response to heat stress (Figure 6). In addition, AtHsfA2a was reported to play a broader role in the expression of multiple Hsps (Hsp70-5, Hsp18.1-Cl, and Hsp22-ER) (Schramm et al., 2006) and general stress-related non-chaperone encoding genes such as GOLS1 or APX2 (Nishizawa-Yokoi et al., 2009), while the FvHsfA2a transcript was clearly up-regulated in response to salt and ABA treatments (Figures 7C, 8). Lastly, while SlHsfA2a, a homolog of FvHsfA2a in tomato, reportedly localizes to the nucleus, interaction with SlHsfA1 is required for the efficient nuclear import of SlHsfA2a (Scharf et al., 1998). This finding is consistent with our results showing that FvHsfA2a-GFP fusion protein also localized to nucleus but could also be detected in the cytosol of Arabidopsis mesophyll protoplasts, which may result from the absence of the specific interaction factor (Figure 4).

FvHsfA3a has orthologs in apple $(M d H s f A 3 a / b / c)$ and has a syntenic gene in Arabidopsis (AtHsfA3a) (Figure 1). MdHsfA3b/c are involved in maintaining the stress response when apple trees were exposed to prolonged periods of high temperature (Giorno et al., 2012). AtHsfA3a expression was regarded as part of the drought stress response (Schramm et al., 2008). SlHsfA3a, a homolog of FvHsfA3a in tomato, is a nuclear-localized Hsf that is induced by heat stress, high salinity, and drought, but not abscisic acid (Li et al., 2013). Our data are highly similar, with FvHsfA3a accumulating during heat, drought, salt, and ethephon treatments (Figures 6, 7B,C, 8) and FvHsfA3a-GFP fusion proteins clearly localized to the nucleus of protoplasts (Figure 4).

FvHsfA4a and FvHsfA5a are intriguing strawberry $H s f s$. FvHsfA $4 a$ and FvHsfA5a were the earliest FvHsfs to diverge from the evolutionary branch, with similar results being found in the Hsf families of other species (Figure 1A). In addition, both FvHsfA4a and FvHsfA5a show significant localization to the cytosol of Arabidopsis mesophyll protoplasts (Figure 4). Notably, FvHsfA4a and FvHsfA5a were both distinctly up-regulated in response to abiotic stress (cold, drought, and salt) (Figure 7) and hormone treatments (ABA, Eth, MeJA, and SA) (Figure 8). The translocation of Hsf proteins from the cytosol to the nucleus is redox-dependent (Giesguth et al., 2015), and AtHsfA4a, an Arabidopsis ortholog of $\mathrm{F} v H s f A 4 a$, has been shown to play a central role in the early sensing of $\mathrm{H}_{2} \mathrm{O}_{2}$ stress in Arabidopsis (Davletova et al., 2005). Thus, we speculate that the dramatically increased expression of FvHsfA4a and FvHsfA5a in response to a range of treatments (Figures 6-8) and the specific cellular localization of FvHsfA4a and FvHsfA5a (Figure 4) may have important implications for stress signaling.

It is notable that FvHsfAGa is an important member of the FvHsf family, with two syntenic AtHsfs in Arabidopsis: $A t H s f A 6 b$ and AtHsfA7b (Figure 1B). Yoshida et al. confirmed that AtHsfA6a/b were involved in ABA-dependent signaling in response to water deficiency stress (Yoshida et al., 2010), and our data also showed that $F v H s f A 6 a$ was highly expressed in response to ABA treatment (Figure 8). Recently, Xue et al. demonstrated that TaHsfA6f, a FvHsfA6a ortholog in Triticum aestivum, serves as a transcriptional activator that regulates a suite of heat stress protection genes in wheat (Xue et al., 2015). This finding is consistent with FvHsfA6a showing high expression under heat treatment and highly specific nuclear localization (Figures 4, 6).

Undoubtedly, FvHsfA9a is a unique member of the FvHsf family. While FvHsfA9a is phylogenetically close to FvHsfA2a (Figure 1A), the expression characteristics of $F v H s f A 9 a$ are entirely different from $\mathrm{FvHsfA2a}$, which was primarily induced 
at the earlier stage of treatments (Figures 6, 7C, 8). In contrast, the current data identified $F v H s f A 9 a$ as a late response factor in long-term heat, drought, salt, and cold stress treatments (Figures 6, 7). The Arabidopsis and Helianthus annuus homologs of FvHsfA9a function as seed-specific sHsp (small heat shock protein) regulators (Kotak et al., 2007; Prieto-Dapena et al., 2008) and are associated with ABA-mediated stress signaling and drought resistance (Schramm et al., 2008). Similarly, FvHsfA9a showed specific nuclear localization (Figure 4) and was only induced in response to ABA (Figure S2).

It is worth noting that $F v H s f B 1 a$ was induced in response to all of the stress or hormone treatments, and was both instantly induced by all stimuli and also reached a high expression level during all of the treatments (Figures 6-8). Bharti et al. provided evidence that $S l H s f B 1$, the tomato ortholog of $F v H s f B 1 a$, represents a novel type of coactivator, cooperating with class A Hsfs or other activators that control housekeeping gene expression during stress conditions (Bharti et al., 2004). Moreover, FvHsfBla was highly induced at the late stage of powdery mildew infection (Figure 7) and accumulated to high levels during SA and MeJA treatments (Figure 8). Similarly, AtHsfB1a, the Arabidopsis homolog of $F v H s f B 1 a$, was reported as a crucial component of salicylic acid-mediated resistance (Kumar et al., 2009; Ikeda et al., 2011; Pick et al., 2012), and subsequent evidence also demonstrated that AtHsfB1a plays a pivotal role in primed defense gene activation and the pathogen-induced acquired immune response (Pick et al., 2012). Therefore, it is reasonable to speculate that $F v H s f B 1 a$ is a key player in the acquired immune response to the biotrophic fungus Podosphaera aphanis.

In addition to stress, Hsfs have also been reported to play roles in plant growth and development (Begum et al., 2013). The detailed expression profiles of individual FvHsfs in six important organs were determined in this study (Figure 5B). Notably, several FvHsfs (FvHsfA2a,A3a,A4a, A5a, A6a, A9a, $B 1 a$, and $C 1 a$ ) exhibited organ-specific distribution and were clearly involved in stress responses (Figure 5A), suggesting that FvHsf members could be important in protecting growing or developing strawberry plants from heat damage.

\section{Conclusion}

In this study, we identified 17 FvHsf genes in a diploid strawberry by employing bioinformatics and publicly available data. The evolutionary relationship and structural feature analyses have aided in identifying the potential functions of individual strawberry $H s f s$ by retrieving clues from the wellinvestigated Arabidopsis. Numerous cis-acting elements were

\section{References}

Almoguera, C., Prieto-Dapena, P., Díaz-Martín, J., Espinosa, J. M., Carranco, R., and Jordano, J. (2009). The HaDREB2 transcription factor enhances basal thermotolerance and longevity of seeds through functional interaction with HaHSFA9. BMC Plant Biol. 9:75. doi: 10.1186/1471-22 29-9-75 found in the FvHsf promoter sequences, suggesting that FvHsf gene expression is controlled by a complex regulatory regime. The gene expression profiles obtained during $42^{\circ} \mathrm{C}, 4^{\circ} \mathrm{C}$, drought, salt, powdery mildew infection, and phytohormone treatments suggest that several strawberry $H s f$ genes (including FvHsfA2a, FvHsfA3a, FvHsfA4a, FvHsfA5a, FvHsfA6a, FvHsfA9a, FvHsfB1a, and $\mathrm{FvHsfCla}$ ) could play important roles in adaptation to environmental stresses. In addition, the distinct subcellular localization of strawberry Hsfs suggests the potential functional divergence of several strawberry Hsfs. Taken together, the present work may provide the basis for further studies to dissect FvHsf function in response to stress stimuli.

\section{Author Contributions}

JF conceived and designed the experiments. YH, WW, and YTH performed the experiments. YH, KZ, WW, and JF analyzed the data. YH, YL, YG, and FZ contributed reagents/materials/analysis tools. YH and JF contributed to the writing of the manuscript. The authors thank Dr. Ke Duan of the Shanghai Academy of Agricultural Sciences for generously providing wild type Fragaria vesca plants.

\section{Acknowledgments}

This work was supported by the National Natural Science Foundation of China (Grant No. 31201657), the Fundamental Research Funds for the Central Universities (QN2013019), and the Shaanxi province science and technology research and development program (2014K02-02-02).

\section{Supplementary Material}

The Supplementary Material for this article can be found online at: http://journal.frontiersin.org/article/10.3389/fpls.2015. 00736

Supplementary Figure S1 | Expression profiles of 17 FvHsf genes in response to abiotic and biotic stress treatments, as determined using semi quantitative RT-PCR.

Supplementary Figure S2 | Expression profiles of 17 FvHsf genes in response to phytohormone treatments, as determined using semi quantitative RT-PCR.

\section{Supplementary Table S1 | The primers used in this study.}

Supplementary Table S2 | The best matches for the protein motif sequences.

Supplementary Table S3 | The syntenic relationships between strawberry and Arabidopsis Hsf genes. 
protein ortholog HAC1. Plant Cell 16, 1521-1535. doi: 10.1105/tpc. 019927

Chan-Schaminet, K. Y., Baniwal, S. K., Bublak, D., Nover, L., and Scharf, K. D. (2009). Specific interaction between tomato HsfA1 and HsfA2 creates hetero-oligomeric superactivator complexes for synergistic activation of heat stress gene expression. J. Biol. Chem. 284, 20848-20857. doi: 10.1074/jbc.M109.007336

Chung, E., Kim, K. M., and Lee, J. H. (2013). Genome-wide analysis and molecular characterization of heat shock transcription factor family in Glycine max. J. Genet. Genomics 40, 127-135. doi: 10.1016/j.jgg.2012.12.002

Clarke, S. M., Cristescu, S. M., Miersch, O., Harren, F. J. M., Wasternack, C., and Mur, L. A. (2009). Jasmonates act with salicylic acid to confer basal thermotolerance in Arabidopsis thaliana. New Phytol. 182, 175-187. doi: 10.1111/j.1469-8137.2008.02735.x

Darwish, O., Shahan, R., Liu, Z. C., Slovin, J. P., and Alkharouf, N. W. (2015). Re-annotation of the woodland strawberry (Fragaria vesca) genome. BMC Genomics 16:29. doi: 10.1186/s12864-015-1221-1

Davletova, S., Rizhsky, L., Liang, H., Shengqiang, Z., Oliver, D. J., Coutu, J., et al. (2005). Cytosolic ascorbate peroxidase 1 is a central component of the reactive oxygen gene network of Arabidopsis. Plant Cell 17, 268-281. doi: 10.1105/tpc.104.026971

de Souza, S. J., Long, M., Kleln, R. J., Roy, S., Lin, S., and Gilbert, W. (1998). Toward a resolution of the introns early/late debate: only phase zero introns are correlated with the structure of ancient proteins. Proc. Natl. Acad. Sci. U.S.A. 95, 5094-5099. doi: 10.1073/pnas.95.9.5094

Deng, Q. L., Ishii, S., and Sarai, A. (1996). Binding site analysis of c-Myb: Screening of potential binding sites by using the mutation matrix derived from systematic binding affinity measurements. Nucleic Acids Res. 24, 766-774. doi: $10.1093 /$ nar/24.4.766

Döring, P., Treuter, E., Kistner, C., Lyck, R., Chen, A., and Nover, L. (2000). The role of AHA motifs in the activator function of tomato heat stress transcription factors HsfA1 and HsfA2. Plant Cell 12, 265-278. doi: 10.1105/tpc.12.2.265

Ghiurcuta, C. G., and Moret, B. M. E. (2014). Evaluating synteny for improved comparative studies. Bioinformatics 30, 9-18. doi: 10.1093/bioinformatics/btu259

Giesguth, M., Sahm, A., Simon, S., and Dietz, K. J. (2015). Redox-dependent translocation of the heat shock transcription factor AtHSFA8 from the cytosol to the nucleus in Arabidopsis thaliana. FEBS Lett. 589, 718-725. doi: 10.1016/j.febslet.2015.01.039

Giorno, F., Guerriero, G., Baric, S., and Mariani, C. (2012). Heat shock transcriptional factors in Malus domestica: identification, classification and expression analysis. BMC Genomics 13:639. doi: 10.1186/1471-216413-639

Guo, J. K., Wu, J., Ji, Q., Wang, C., Luo, L., Yuan, Y., et al. (2008). Genomewide analysis of heat shock transcription factor families in rice and Arabidopsis. J. Genet. Genomics 35, 105-118. doi: 10.1016/S1673-8527(08)60016-8

Hahn, A., Bublak, D., Schleiff, E., and Scharf, K. D. (2011). Crosstalk between Hsp90 and Hsp70 chaperones and heat stress transcription factors in tomato. Plant Cell 23, 741-755. doi: 10.1105/tpc.110.076018

Harrison, C. J., Bohm, A. A., and Nelson, H. C. M. (1994). Crystal-structure of the DNA-binding domain of the heat-shock transcription factor. Science 263, 224-227. doi: $10.1126 /$ science. 8284672

Hedhly, A., Hormaza, J. I., and Herrero, M. (2009). Global warming and sexual plant reproduction. Trends Plant Sci. 14, 30-36. doi: 10.1016/j.tplants.2008.11.001

Heerklotz, D., Döring, P., Bonzelius, F., Winkelhaus, S., and Nover, L. (2001). The balance of nuclear import and export determines the intracellular distribution and function of tomato heat stress transcription factor HsfA2. Mol. Cell. Biol. 21, 1759-1768. doi: 10.1128/MCB.21.5.1759-1768.2001

Hwang, S. M., Kim, D. W., Woo, M. S., Jeong, H. S., Son, Y. S., Akhter, S., et al. (2014). Functional characterization of Arabidopsis HsfA6a as a heat-shock transcription factor under high salinity and dehydration conditions. Plant Cell Environ. 37, 1202-1222. doi: 10.1111/pce.12228

Ikeda, M., Mitsuda, N., and Ohme-Takagi, M. (2011). Arabidopsis HsfB1 and $\mathrm{HsfB} 2 \mathrm{~b}$ act as repressors of the expression of heat-inducible Hsfs but positively regulate the acquired thermotolerance. Plant Physiol. 157, 1243-1254. doi: $10.1104 /$ pp.111.179036
Jiang, C., Iu, B., and Singh, J. (1996). Requirement of a CCGAC cis-acting element for cold induction of the BN115 gene from winter Brassica napus. Plant Mol. Biol. 30, 679-684. doi: 10.1007/BF00049344

Kotak, S., Port, M., Ganguli, A., Bicker, F., and Von Koskull-Döring, P. (2004). Characterization of C-terminal domains of Arabidopsis heat stress transcription factors (Hsfs) and identification of a new signature combination of plant class A Hsfs with AHA and NES motifs essential for activator function and intracellular localization. Plant J. 39, 98-112. doi: 10.1111/j.1365-313X.2004. 02111.x

Kotak, S., Vierling, E., Baumlein, H., and Von Koskull-Döring, P. (2007). A novel transcriptional cascade regulating expression of heat stress proteins during seed development of Arabidopsis. Plant Cell 19, 182-195. doi: 10.1105/tpc.106.048165

Kumar, M., Busch, W., Birke, H., Kemmerling, B., Nürnberger, T., and Schöffl, F. (2009). Heat shock factors $\mathrm{HsfB} 1$ and $\mathrm{HsfB} 2 \mathrm{~b}$ are involved in the regulation of Pdf1.2 expression and pathogen resistance in Arabidopsis. Mol. Plant 2, 152-165. doi: 10.1093/mp/ssn095

Lee, T. H., Tang, H. B., Wang, X. Y., and Paterson, A. H. (2013). PGDD: a database of gene and genome duplication in plants. Nucleic Acids Res. 41, D1152-D1158. doi: 10.1093/nar/gks1104

Littlefield, O., and Nelson, H. C. M. (1999). A new use for the 'wing' of the 'winged' helix-turn-helix motif in the HSF-DNA cocrystal. Nat. Struct. Biol. 6, 464-470. doi: 10.1038/8269

Li, Z ., Zhang, L., Wang, A., Xu, X., and Li, J. (2013). Ectopic overexpression of SlHsfA3, a heat stress transcription factor from tomato, confers increased thermotolerance and salt hypersensitivity in germination in transgenic Arabidopsis. PLoS ONE 8:e54880. doi: 10.1371/journal.pone.0054880

Liu, H., Xie, W. F., Zhang, L., Valpuesta, V., Ye, Z. W., Gao, Q. H., et al. (2014). Auxin biosynthesis by the YUCCA6 flavin monooxygenase gene in woodland strawberry. J. Integr. Plant Biol. 56, 350-363. doi: 10.1111/jipb.12150

Lyck, R., Harmening, U., Höhfeld, I., Treuter, E., Scharf, K. D., and Nover, L. (1997). Intracellular distribution and identification of the nuclear localization signals of two plant heat-stress transcription factors. Planta 202, 117-125. doi: $10.1007 / \mathrm{s} 004250050110$

Maughan, T. L., Black, B. L., and Drost, D. (2015). Critical temperature for sub-lethal cold injury of strawberry leaves. Sci. Hortic. 183, 8-12. doi: 10.1016/j.scienta.2014.12.001

Mayer, K. F. X., Rogers, J., Dolezel, J., Pozniak, C., Eversole, K., Feuillet, C., et al. (2014). A chromosome-based draft sequence of the hexaploid bread wheat (Triticum aestivum) genome. Science 345, 286. doi: 10.1126/science.1251788

Mittal, D., Chakrabarti, S., Sarkar, A., Singh, A., and Grover, A. (2009). Heat shock factor gene family in rice: genomic organization and transcript expression profiling in response to high temperature, low temperature and oxidative stresses. Plant Physiol. Biochem. 47, 785-795. doi: 10.1016/j.plaphy.2009.05.003

Mittler, R., Finka, A., and Goloubinoff, P. (2012). How do plants feel the heat? Trends Biochem. Sci. 37, 118-125. doi: 10.1016/j.tibs.2011.11.007

Never, L., Scharf, K. D., Gagliardi, D., Vergne, P., Czarneckaverner, E., and Gurley, W. B. (1996). The Hsf world: classification and properties of plant heat stress transcription factors. Cell Stress Chaperones 1, 215-223.

Nezhadahmadi, A., Faruq, G., and Rashid, K. (2015). The impact of drought stress on morphological and physiological parameters of three strawberry varieties in different growing conditions. Pak. J. Agric. Sci. 52, 79-92.

Nishizawa-Yokoi, A., Yoshida, E., Yabuta, Y., and Shigeoka, S. (2009). Analysis of the regulation of target genes by an Arabidopsis heat shock transcription factor, HsfA2. Biosci. Biotechnol. Biochem. 73, 890-895. doi: 10.1271/bbb. 80809

Pick, T., Jaskiewicz, M., Peterhansel, C., and Conrath, U. (2012). Heat shock factor HsfB1 primes gene transcription and systemic acquired resistance in Arabidopsis. Plant Physiol. 159, 52-55. doi: 10.1104/pp.111.191841

Prieto-Dapena, P., Castano, R., Almoguera, C., and Jordano, J. (2008). The ectopic overexpression of a seed-specific transcription factor, HaHSFA9, confers tolerance to severe dehydration in vegetative organs. Plant J. 54, 1004-1014. doi: 10.1111/j.1365-313X.2008.03465.X

Raab, T., Lopez-Raez, J. A., Klein, D., Caballero, J. L., Moyano, E., Schwab, W., et al. (2006). FaQR, required for the biosynthesis of the strawberry flavor compound 4-hydroxy-2,5-dimethyl-3(2H)-furanone, encodes an enone oxidoreductase. Plant Cell 18, 1023-1037. doi: 10.1105/tpc.105.039784 
Ren, J., Wen, L. P., Gao, X. J., Jin, C. J., Xue, Y., and Yao, X. B. (2009). DOG 1.0: illustrator of protein domain structures. Cell Res. 19, 271-273. doi: $10.1038 / \mathrm{cr} .2009 .6$

Rombauts, S., Dehais, P., Van Montagu, M., and Rouze, P. (1999). PlantCARE, a plant cis-acting regulatory element database. Nucleic Acids Res. 27, 295-296. doi: 10.1093/nar/27.1.295

Scharf, K. D., Berberich, T., Ebersberger, I., and Nover, L. (2012). The plant heat stress transcription factor (Hsf) family: structure, function and evolution. Biochim. Biophys. Acta 1819, 104-119. doi: 10.1016/j.bbagrm.2011.10.002

Scharf, K. D., Heider, H., Hohfeld, I., Lyck, R., Schmidt, E., and Nover, L. (1998). The tomato Hsf system: HsfA2 needs interaction with HsfA1 for efficient nuclear import and may be localized in cytoplasmic heat stress granules. Mol. Cell. Biol. 18, 2240-2251.

Schmutz, J., Cannon, S. B., Schlueter, J., Ma, J. X., Mitros, T., Nelson, W., et al. (2010). Genome sequence of the palaeopolyploid soybean. Nature 463, 178-183. doi: 10.1038/nature08670

Schramm, F., Ganguli, A., Kiehlmann, E., Englich, G., Walch, D., and Von Koskull-Doring, P. (2006). The heat stress transcription factor HsfA2 serves as a regulatory amplifier of a subset of genes in the heat stress response in Arabidopsis. Plant Mol. Biol. 60, 759-772. doi: 10.1007/s11103-0055750-x

Schramm, F., Larkindale, J., Kiehlmann, E., Ganguli, A., Englich, G., Vierling, E., et al. (2008). A cascade of transcription factor DREB2A and heat stress transcription factor HsfA3 regulates the heat stress response of Arabidopsis. Plant J. 53, 264-274. doi: 10.1111/j.1365-313X.2007. 03334.x

Schwartz, S., Meshorer, E., and Ast, G. (2009). Chromatin organization marks exon-intron structure. Nat. Struct. Mol. Biol. 16, 990-995. doi: 10.1038/nsmb.1659

Schwechheimer, C., and Bevan, M. (1998). The regulation of transcription factor activity in plants. Trends Plant Sci. 3, 378-383. doi: 10.1016/S13601385(98)01302-8

Shen, Z., Yao, J., Sun, J., Chang, L., Wang, S., Ding, M., et al. (2015). Populus euphratica HSF binds the promoter of WRKY1 to enhance salt tolerance. Plant Sci. 235, 89-100. doi: 10.1016/j.plantsci.2015.03.006

Shim, D., Hwang, J. U., Lee, J., Lee, S., Choi, Y., An, G., et al. (2009). Orthologs of the Class A4 heat shock transcription factor HsfA4a confer cadmium tolerance in wheat and rice. Plant Cell 21, 4031-4043. doi: 10.1105/tpc.109.066902

Shulaev, V., Sargent, D. J., Crowhurst, R. N., Mockler, T. C., Folkerts, O., Delcher, A. L., et al. (2011). The genome of woodland strawberry (Fragaria vesca). Nat. Genet. 43, 109-116. doi: 10.1038/ng.740
Tamura, K., Peterson, D., Peterson, N., Stecher, G., Nei, M., and Kumar, S. (2011) MEGA5: molecular evolutionary genetics analysis using maximum likelihood, evolutionary distance, and maximum parsimony methods. Mol. Biol. Evol. 28, 2731-2739. doi: 10.1093/molbev/msr121

Velasco, R., Zharkikh, A., Affourtit, J., Dhingra, A., Cestaro, A., Kalyanaraman, A., et al. (2010). The genome of the domesticated apple (Malus $\mathrm{x}$ domestica Borkh.). Nat. Genet. 42, 833-839. doi: 10.1038/ng.654

Von Koskull-Doring, P., Scharf, K. D., and Nover, L. (2007). The diversity of plant heat stress transcription factors. Trends Plant Sci. 12, 452-457. doi: 10.1016/j.tplants.2007.08.014

Xue, G. P., Drenth, J., and Mcintyre, C. L. (2015). TaHsfA6f is a transcriptional activator that regulates a suite of heat stress protection genes in wheat (Triticum aestivum L.) including previously unknown Hsf targets. J. Exp. Bot. 66, 1025-1039. doi: 10.1093/jxb/eru462

Xue, G. P., Sadat, S., Drenth, J., and Mcintyre, C. L. (2014). The heat shock factor family from Triticum aestivum in response to heat and other major abiotic stresses and their role in regulation of heat shock protein genes. J. Exp. Bot. 65, 539-557. doi: 10.1093/jxb/ert399

Yoo, S. D., Cho, Y. H., and Sheen, J. (2007). Arabidopsis mesophyll protoplasts: a versatile cell system for transient gene expression analysis. Nat. Protoc. 2, 1565-1572. doi: 10.1038/nprot.2007.199

Yoshida, T., Fujita, Y., Sayama, H., Kidokoro, S., Maruyama, K., Mizoi, J., et al. (2010). AREB1, AREB2, and ABF3 are master transcription factors that cooperatively regulate $\mathrm{ABRE}$-dependent $\mathrm{ABA}$ signaling involved in drought stress tolerance and require ABA for full activation. Plant J. 61, 672-685. doi: 10.1111/j.1365-313X.2009.04092.X

Zhang, K., Han, Y. T., Zhao, F. L., Hu, Y., Gao, Y. R., Ma, Y. F., et al. (2015) Genome-wide identification and expression analysis of the CDPK gene family in grape, Vitis spp. BMC Plant Biol. 15:164. doi: 10.1186/s12870-015-0552-z

Conflict of Interest Statement: The authors declare that the research was conducted in the absence of any commercial or financial relationships that could be construed as a potential conflict of interest.

Copyright (c) $2015 \mathrm{Hu}$, Han, Wei, Li, Zhang, Gao, Zhao and Feng. This is an openaccess article distributed under the terms of the Creative Commons Attribution License (CC BY). The use, distribution or reproduction in other forums is permitted, provided the original author(s) or licensor are credited and that the original publication in this journal is cited, in accordance with accepted academic practice. No use, distribution or reproduction is permitted which does not comply with these terms. 